\title{
Princípios cooperativistas na percepção dos associados: estudo de caso em uma cooperativa de crédito de Minas Gerais
}

\section{Cooperative principles in perception of the associates: case study in a credit cooperative of Minas Gerais}

DOI: $10.46814 / \operatorname{lajdv2n1-001}$

Recebimento dos originais: 01/01/2020

Aceitação para publicação: 10/01/2020

\section{Jaciara Xavier Pereira Ribeiro}

Doutoranda em Ciências da Educação pela Instituição Brasil de Educação e Pesquisa - IBEP, em parceria com a Universidade Nacional de La Plata e Universidade Del Sol

Instituição: Instituição Brasil de Educação e Pesquisa - IBEP, em parceria com a Universidade Nacional de La Plata e Universidade Del Sol - UNADES/IBEP/BRASIL

Endereço: UNADES - 14 De Mayo 462, Asunción, Paraguai/ IBEP - sede no Calçadão Arthur Bernardes, $\mathrm{n}^{\circ}$ 152, Sala 06, Bairro Centro, Viçosa - MG - CEP 36.570- 061

E-mail: jaciaraxp@yahoo.com.br

\section{Alfredo Alves de Oliveira Melo}

Doutor em Ciências das Organizações pela Université Paris-Dauphine - Paris IX, DAUPHINE, França Instituição: Université Paris-Dauphine - Paris IX, DAUPHINE, França

Endereço: Place du Maréchal de Lattre de Tassigny, 75016 Paris, França

E-mail: diretoria@unihorizontes.br

\section{RESUMO}

O Cooperativismo é um modelo de organização que tem como objetivo principal o desenvolvimento econômico e social, tendo em seus princípios as linhas orientadoras através dos quais as cooperativas levam os seus valores à prática. Os sete princípios cooperativos são: adesão voluntária e livre; gestão democrática pelos membros; participação econômica dos membros; autonomia e independência: educação, formação e informação; intercooperação e interesse pela comunidade. O objetivo geral é avaliar o grau de aderência dos associados de uma cooperativa de crédito de livre admissão de Minas Gerais no que diz respeito aos princípios cooperativistas. A pergunta que orientou o trabalho: qual o grau de aderência dos associados com relação aos princípios cooperativistas? Este trabalho foi realizado através da abordagem quantitativa descritiva por meio de um survey. A população total foi de 11.789 associados e amostra de 373 associados. O nível de significância foi de 5\%, e confiabilidade de 95\%. Os sujeitos da pesquisa foram os associados. A técnica de coleta de dados foi o questionário, utilizando a escala de avaliação likert. Para a análise dos dados foram usados os softwares estatísticos Minitab 15 e SPSS 16, além do Microsoft Excel, nos quais foram realizadas análises de ordem univariada e bivariada através do estudo das médias. Os objetivos estabelecidos foram atingidos, sendo respondida a questão problema do estudo. Diante dos resultados apresentados, conclui-se que os associados da cooperativa pesquisada apresentaram elevado grau de aderência no que diz respeito aos princípios cooperativistas.

Palavras-chave: Cooperativismo, Princípios cooperativistas, Cooperativa, Aderência. 


\begin{abstract}
Cooperativism is an organizational model that has as main objective the economic and social development, having in its principles the guiding lines through which the cooperatives take their values to practice. The seven cooperative principles are: voluntary and free membership; democratic management by members; economic participation of members; autonomy and independence: education, training and information; intercooperation and interest in the community. The general objective is to evaluate the degree of adherence of members of a credit union of free admission in Minas Gerais with regard to cooperative principles. The question that guided the work: what is the degree of adherence of members in relation to cooperative principles? This work was carried out through the quantitative descriptive approach through a survey. The total population was 11,789 members and a sample of 373 members. The level of significance was $5 \%$, and $95 \%$ reliability. The research subjects were the associates. The data collection technique was the questionnaire, using the likert rating scale. Statistical software Minitab 15 and SPSS 16 were used for data analysis, in addition to Microsoft Excel, in which univariate and bivariate analyzes were performed through the study of means. The established objectives were achieved, and the question of the study was answered. In view of the results presented, it is concluded that the members of the researched cooperative showed a high degree of adherence with regard to cooperative principles.
\end{abstract}

Key words: Cooperativism, Cooperative principles, Cooperative, Adherence.

\title{
1 INTRODUÇÃO
}

O Cooperativismo é um modelo de organização cujo objetivo principal é o desenvolvimento econômico e social. Os verbetes associativismo e cooperativismo estão interligados de forma inseparável, indicando uma associação de pessoas de determinado seguimento econômico ou social, com finalidade de desempenhar, em benefício comum, alguma atividade econômica (BIALOSKORSKI NETO, 2002).

Os sete princípios cooperativos são: adesão voluntária e livre; gestão democrática pelos cooperados; participação econômica dos cooperados; autonomia e independência; educação, formação e informação; cooperação entre cooperativas e interesse pela comunidade. Estes princípios são as linhas orientadoras através das quais as cooperativas levam os seus valores ${ }^{1}$ à prática (GAWLAK; RATZKE, 2001).

O presente estudo foi desenvolvido em uma cooperativa de crédito de livre admissão ${ }^{2}$. Segundo Pinheiro (2008, p.7), estas são instituições financeiras constituídas sob a forma de sociedade cooperativa, tendo por objetivo a prestação de serviços financeiros aos associados.

Segundo Polonio (1999, p.23), as principais vantagens obtidas por um membro associado de uma cooperativa de crédito são o acesso a crédito a juros mais baixos e serviços financeiros com taxas menores, apresentando melhores condições de retorno de investimentos e aplicações, além de o associado receber orientação financeira. Este, também chamado de cooperado, possui caráter duplo, ao ser

Os valores baseiam-se em ajuda mútua e responsabilidade, democracia, igualdade, equidade e solidariedade (OLIVEIRA, 2001, p.319).

A livre admissão é um dos critérios de admissão de associados em uma cooperativa de crédito, nas quais coexistem grupos de associados de diversas origens e atividades econômicas, definidos na resolução 3859/2000 - Banco Central do Brasil. 
proprietário e usuário dos seus serviços, o que lhe proporciona possibilidade de participação nos resultados, de acordo com as operações na cooperativa.

A aderência dos princípios cooperativos por parte dos associados fortalece o ideal cooperativista, pois representa o diferencial destas com relação às outras instituições financeiras (VALADARES, 2003, p.38).

Pelas vantagens sugeridas por Polonio (1999, p.23) com relação ao cooperativismo de crédito, o desejável seria uma maior participação das cooperativas no mercado financeiro brasileiro, que segundo informações do Banco Central, foi de apenas 2.2\% em junho de 2011. Para Nascimento (2000, p.209), a maioria dos problemas enfrentados pelas cooperativas, inclusive financeiros e gerenciais, pode ser resolvida com a maior participação de todos os envolvidos, e isto passa pelo grau de aderência por parte dos associados aos princípios e valores das cooperativas.

Para Pinheiro (2008, p. 8), apesar do potencial de crescimento do segmento no Brasil e da importância que esse vem adquirindo, ainda é grande o desconhecimento sobre as políticas cooperativistas por parte do público em geral.

Segundo Holzmann (2001), no entanto, a baixa participação de associados nas assembleias, principalmente os de baixo grau de instrução, demanda ações a fim de melhorar a qualidade das informações e da comunicação, visando a integração entre os associados, deles com a cooperativa e viceversa, para que tornem-se agentes ativos nas assembleias (ARAÚJO; SILVA, 2010, p.4).

Sendo assim, para a definição do problema de pesquisa levou-se em consideração a expectativa de investigar a aderência dos associados sobre os princípios que regem o cooperativismo. O problema é expresso, então, pela questão: qual o grau de aderência dos associados com relação aos princípios cooperativistas? Tendo como objetivo geral avaliar o grau de aderência dos associados de uma cooperativa de crédito de livre admissão de Minas Gerais no que diz respeito aos princípios cooperativistas e os objetivos específicos são: identificar o perfil dos associados; analisar a compreensão dos associados quanto às doutrinas cooperativistas; apurar a existência de ações adotadas pela organização com vistas a divulgar os princípios cooperativistas aos associados.

Vergara (2005, p.32) aborda que o autor de um estudo justifica-o ao atribuir-lhe contribuições de ordem prática ou ao estado da arte na área. Neste sentido o presente trabalho poderá trazer como contribuição prática, o conhecimento da aderência aos princípios cooperativistas por parte dos associados.

Este artigo está estruturado em sete capítulos, incluindo a introdução, na qual se apresenta o problema de pesquisa, os objetivos, a justificativa e a estrutura do artigo. Os demais capítulos organizamse da seguinte maneira: no segundo aborda-se sobre o cooperativismo; no terceiro trata-se dos princípios cooperativistas, no quarto trata-se da gestão das cooperativas, no quinto desenvolve-se a metodologia, com a apresentação do caso estudado; o sexto é dedicado à análise dos resultados; no sétimo formulam-se 
as conclusões, acrescidas das limitações e sugestões para novos estudos, após é apresentado o resumo em língua vernácula, e por fim são apresentadas as referências bibliográficas.

\section{COOPERATIVISMO}

O cooperativismo é tido como um dos principais instrumentos para a promoção de desenvolvimento econômico e social, pois gera e distribui renda e promove o capital social nas comunidades que o praticam (BIALOSKORSKI NETO, 2002, p.77:97).

A respeito do surgimento do cooperativismo, Correia e Moura (2001, p.5) e Braga (2001) afirmam que a doutrina do cooperativismo teve origem no final do século XVIII e metade do século XIX, na Inglaterra, época da Revolução Industrial, onde havia muitas fábricas repletas de operários carregados de problemas e necessidades, pois, enquanto as fábricas prosperavam, os operários viviam quase na miséria: muitas horas de trabalho, salários muito baixos, desemprego, fome, etc. Em meio a todos estes problemas alguns operários resolveram reunir-se para procurar uma solução, e sentiram que só através da cooperação poderiam sobreviver à crise. Através da união de 28 tecelões (operários) foi criado, então, um pequeno armazém cooperativo de consumo, a "Sociedade dos Equitativos Pioneiros de Rochdale". Assim foi lançada, em Rochdale, no ano de 1844, a semente do Cooperativismo.

Em um período curto de tempo estes tecelões começaram a se profissionalizar, elaborando estratégias como aquisição de casas para os associados, formação de um capital social para emancipação dos trabalhadores e criação de estabelecimentos industriais e agrícolas para a produção de bens indispensáveis a preços baixos. Enquanto a lógica do capitalismo instituía a competição, o novo sistema estimulava a cooperação (SANTOS, 2002, p. 11).

Para Rech (2000, p.144-5) o cooperativismo tem características similares no mundo todo, tendo posição a partir das óticas capitalista e socialista; na visão capitalista atenuam-se as características de concentração de capital, e na visão socialista surge como alternativa de uma nova ordem econômica e social.

Segundo Barros et al (2005, p. 2158), cooperativa é uma associação autônoma de pessoas que se unem voluntariamente, visando satisfazer aspirações e necessidades econômicas, sociais e culturais comuns, por meio de uma empresa de propriedade coletiva e democraticamente gerida.

O Brasil apresentou, no ano de 2010, um total de 6.643 cooperativas distribuídas em todos os estados, com destaque para São Paulo, com 13,7\%, Minas Gerais, com 11,6\%, Rio Grande do Sul, com 10,9\%, e Bahia, com 9.9\%, 9.016.527 associados e 298.182 empregados em todo o Brasil (OCEMG, 2011, p.10). 
A Organização das Cooperativas Brasileiras (OCB) classifica as cooperativas do Brasil em treze ramos distintos: agropecuário, consumo, crédito, educacional, especial, habitacional, infraestrutura, mineral, produção, saúde, trabalho, transporte e turismo e lazer (OCEMG, 2011, p.8:9).

Quadro 1 - Diferença entre bancos e cooperativas de crédito

\begin{tabular}{|c|c|}
\hline Bancos & Cooperativas de Crédito \\
\hline 1. São sociedades de capital. & 1. São sociedades de pessoas. \\
\hline $\begin{array}{l}\text { 2. O poder é exercido na proporção do número de } \\
\text { ações. }\end{array}$ & 2. O voto tem peso igual para todos (uma pessoa, um voto). \\
\hline 3. As deliberações são concentradas. & 3. As decisões são compartilhadas entre os associados. \\
\hline $\begin{array}{l}\text { 4. O administrador é um terceiro (profissional de } \\
\text { mercado). }\end{array}$ & 4. $\mathrm{O}$ administrador é o associado. \\
\hline 5. O usuário das operações é mero cliente. & 5. O usuário é o próprio dono (associado). \\
\hline $\begin{array}{l}\text { 6. O usuário não exerce qualquer influência na } \\
\text { definição do preço dos produtos. }\end{array}$ & $\begin{array}{l}\text { 6. Toda política operacional é decidida pelos usuários/donos } \\
\text { (associados). }\end{array}$ \\
\hline 7. Podem tratar distintamente cada usuário. & 7. Não podem distinguir: o que vale para um, vale para todos. \\
\hline 8. Priorizam os grandes centros. & $\begin{array}{l}\text { 8. Não restringem, tendo forte atuação nas comunidades mais } \\
\text { remotas. }\end{array}$ \\
\hline 9. Têm propósitos mercantilistas. & 9. A mercancia não é cogitada. \\
\hline $\begin{array}{l}\text { 10. A remuneração das operações e dos serviços } \\
\text { não tem parâmetro/limite. }\end{array}$ & $\begin{array}{l}\text { 10. O preço das operações e dos serviços visa à cobertura de } \\
\text { custos (taxa de administração). }\end{array}$ \\
\hline $\begin{array}{l}\text { 11. Atendem em massa, priorizando o auto- } \\
\text { serviço. }\end{array}$ & $\begin{array}{l}\text { 11. O relacionamento é personalizado ou individual, com o } \\
\text { apoio da informática. }\end{array}$ \\
\hline $\begin{array}{l}\text { 12. Não têm vínculo com a comunidade e o } \\
\text { público-alvo. }\end{array}$ & 12. Estão comprometidas com a comunidade e os usuários. \\
\hline 13. Avançam pela competição. & 13. Desenvolvem-se pela cooperação. \\
\hline 14. Visam ao lucro por excelência. & 14. O lucro está fora do seu objeto. \\
\hline $\begin{array}{l}\text { 15. O resultado é de poucos donos/ acionistas } \\
\text { (nada é dividido com os clientes). }\end{array}$ & 15. São reguladas pela Lei Cooperativista. \\
\hline $\begin{array}{l}\text { 16. No plano societário, são regulados pela Lei das } \\
\text { Sociedades Anônimas. }\end{array}$ & guladas pela Lei $5764 / 71$. \\
\hline
\end{tabular}

Fonte: LEITE; SENRA, 2005, p.174.

Para Leite e Senra (2005, p. 174), as cooperativas de crédito possuem diferenças com relação aos bancos, as quais são apresentadas no Quadro 1.

Pelo fato do estudo ter sido realizado em uma cooperativa de crédito, estaremos definindo apenas este ramo, que segundo Pinheiro (2008, p.7), as cooperativas de crédito são instituições financeiras constituídas sob a forma de sociedade cooperativa, tendo por objetivo a prestação de serviços financeiros aos associados.

As diferenças entre banco e cooperativas de crédito, apresentadas no Quadro 1, deveriam proporcionar uma maior participação que segundo Rievers (2006), apenas 2\% da População Economicamente Ativa (PEA) do Brasil usufrui dos empréstimos das cooperativas de crédito. Isso retrata o baixo envolvimento da sociedade brasileira com essas organizações, que estão presentes no país há mais de um século, o que leva a considerar que um número bem maior de pessoas poderia beneficiar-se do microcrédito (ARAÚJO; SILVA, 2011, p. 121). 
Os principais sistemas cooperativos de crédito no Brasil são Sicoob, Sicredi, Unicred, Cresol. O Sicoob destaca-se atualmente como o maior e mais estruturado sistema de cooperativas de crédito do Brasil. O Banco Cooperativo Sicredi é a instituição financeira que representa as cooperativas singulares do Sicredi no sistema financeiro nacional, já o Banco Cooperativo do Brasil S.A. (BANCOOB) é um banco comercial privado especializado no atendimento às cooperativas de crédito, cujo controle acionário pertence a entidades filiadas ao Sicoob (ARAÚJO; SILVA, 2011, p. 125).

\section{PRINCÍPIOS COOPERATIVISTAS}

O cooperativismo está embasado em sete princípios, quais sejam: adesão voluntária e livre, gestão democrática pelos membros, participação econômica dos membros, autonomia e independência, educação, formação e informação, intercooperação, interesse pela comunidade. (STEFANO; ZAMPIER; GRZESZCZESZYN, 2006). Estes princípios veem se modificando ao longo dos tempos.

O Quadro 2 apresenta a evolução dos princípios cooperativistas ${ }^{3}$ propostos pela Aliança Cooperativa Internacional (ACI), apresentando os princípios originais de Rochdale e as revisões realizadas nos anos de 1937, 1966 e 1995.

Quadro 2- Evolução dos princípios cooperativistas propostos pela ACI

\begin{tabular}{|c|c|c|c|}
\hline $\begin{array}{c}\text { Princípios originais de } \\
\text { Rochdale (1844) }\end{array}$ & $\begin{array}{c}\text { Revisão de } 1937 \\
\text { (Paris) }\end{array}$ & $\begin{array}{c}\text { Revisão de } 1966 \\
\text { (Viena) }\end{array}$ & $\begin{array}{l}\text { Revisão de } 1995 \\
\text { (Manchester) }\end{array}$ \\
\hline $\begin{array}{l}\text { 1. Adesão aberta de novos } \\
\text { membros no mesmo pé de } \\
\text { igualdade dos antigos. }\end{array}$ & $\begin{array}{l}\text { 1. Adesão aberta de novos } \\
\text { membros no mesmo pé de } \\
\text { igualdade dos antigos. }\end{array}$ & $\begin{array}{l}\text { 1. Adesão livre (inclusive } \\
\text { neutralidade política, religiosa, } \\
\text { racional e social). }\end{array}$ & $\begin{array}{l}\text { 1. Adesão voluntária e } \\
\text { livre. }\end{array}$ \\
\hline $\begin{array}{l}\text { 2. Gestão democrática, um } \\
\text { sócio, um voto. }\end{array}$ & $\begin{array}{l}\text { 2. Gestão democrática, um } \\
\text { sócio, um voto. }\end{array}$ & $\begin{array}{l}\text { 2. Gestão democrática, um sócio, } \\
\text { um voto. }\end{array}$ & $\begin{array}{l}\text { 2. Gestão democrática pelos } \\
\text { membros. }\end{array}$ \\
\hline $\begin{array}{l}\text { 3. Distribuição de parte do } \\
\text { excedente proporcional às } \\
\text { compras. }\end{array}$ & $\begin{array}{l}\text { 3. Distribuição de parte do } \\
\text { excedente proporcional às } \\
\text { compras. }\end{array}$ & $\begin{array}{l}\text { 3. Distribuição das sobras ao(s): } \\
\text { a) desenvolvimento da } \\
\text { cooperativa; } \\
\text { b) serviços comuns; } \\
\text { c) associados pró rata das } \\
\text { operações. } \\
\end{array}$ & $\begin{array}{l}\text { 3. Participação econômica } \\
\text { dos membros. }\end{array}$ \\
\hline $\begin{array}{l}\text { 4. Juros limitados ou } \\
\text { fixados sobre o capital } \\
\text { subscrito. }\end{array}$ & $\begin{array}{l}\text { 4. Juros limitados ou fixados } \\
\text { sobre o capital subscrito. }\end{array}$ & $\begin{array}{l}\text { 4. Taxa limitada de juros ao } \\
\text { capital social. }\end{array}$ & $\begin{array}{l}\text { 4. Autonomia e } \\
\text { Independência. }\end{array}$ \\
\hline 5. Promoção da educação. & -- & $\begin{array}{l}\text { 5. Educação cooperativista } \\
\text { permanente. }\end{array}$ & $\begin{array}{l}\text { 5. Educação, formação e } \\
\text { informação. }\end{array}$ \\
\hline $\begin{array}{l}\text { 6. Vendas à vista, sem } \\
\text { crediário. }\end{array}$ & -- & $\begin{array}{l}\text { 6. Cooperação entre } \\
\text { cooperativas. }\end{array}$ & 6. Intercooperação. \\
\hline $\begin{array}{l}\text { 7. Neutralidade política e } \\
\text { religiosa. }\end{array}$ & -- & $\begin{array}{l}\text { 7. Neutralidade social, política, } \\
\text { religiosa e racial. }\end{array}$ & $\begin{array}{l}\text { 7. Interesse pela } \\
\text { comunidade. }\end{array}$ \\
\hline
\end{tabular}

Fonte: ACI, 2011.

3 São as linhas orientadoras por meio das quais as cooperativas levam os seus valores à prática OCB (2009, p.150). 
Com base na revisão de 1995, os três primeiros princípios representam a dinâmica interna da cooperativa, que trata a questão da associação das pessoas à cooperativa, do controle democrático e participação econômica por parte do associado e os três últimos dizem respeito às condutas que intensificam as relações externas da cooperativa. O quarto princípio complementa os três primeiros e afirma a responsabilidade da cooperativa perante os três últimos, por apresentar independência e autonomia dos associados (ACI, 2011).

Por apresentarem, em sua essência, ideais socialistas, alguns desses princípios vêm sendo modificados ou abandonados ao longo do tempo diante da necessidade de adaptação às transformações capitalistas, conforme apresentado no Quadro 2.

Autores como Jank e Nassar (1995, p.13-32) e Zylbersztajn (1994, p.23-32) acreditam que a solução para aumentar a participação de mercado das cooperativas seria reformar ${ }^{4}$ os princípios do cooperativismo e adotar estratégias de gestão semelhantes às dos bancos. Os autores acreditam que a essência socialista de alguns princípios cooperativos impede o crescimento das organizações, defendendo que estes devem ser adaptados para que as cooperativas consigam competir em um mundo globalizado e capitalista.

Outros autores, como Schneider (2007, p.13) e Alves (2003, p.37), acreditam que a doutrina cooperativista traz mais vantagens do que desvantagens, e que seus princípios podem levar à maior competitividade, defendendo que a relação de compromisso entre cooperativa e cooperado não pode basear-se apenas na força do estatuto, devendo ser construída pela confiança de que a cooperativa é capaz de satisfazer as necessidades de seus membros.

Os princípios de adesão voluntária e livre e gestão democrática vêm sofrendo críticas, e existe pressão para que sejam reformulados na tentativa de imprimir a racionalidade econômica e administrativa nas cooperativas, buscando eficácia interna e externa e permitindo que alcancem maior competitividade em relação às empresas não cooperativas (ACI, 2011).

Os princípios que foram aprovados em Manchester e que devem nortear a prática do cooperativismo nos diversos países em que ela existe são de acordo com Stefano; Zampier; Grzeszczeszyn (2006); Ocemg (2011) e Valadares (2002a, p.21-22) relatam que:

a) adesão voluntária e livre, as cooperativas são organizações voluntárias, abertas a todas as pessoas aptas a utilizar os seus serviços e assumir as responsabilidades como membros, sem discriminações de gênero, sociais, raciais, políticas e religiosas.

b) gestão democrática pelos cooperados, e rege que as cooperativas sejam organizações democráticas, controladas pelos seus membros, que participam ativamente na formulação das suas

${ }^{4}$ Última revisão dos princípios cooperativistas ocorreu no ano de 1995 (ACI, 2011). 
políticas e na tomada de decisões. Nas cooperativas de primeiro grau ${ }^{5}$ (singulares) os membros têm igual direito de voto (um membro, um voto), e as cooperativas de grau superior (centrais, federações e confederações) são também organizadas de forma democrática.

c) participação econômica dos cooperados, que contribuem equitativamente para o capital das suas cooperativas e controlam-no democraticamente. Parte desse capital é normalmente propriedade comum da cooperativa. Os cooperados recebem uma remuneração limitada ao capital integralizado como condição de sua adesão, e destinam os excedentes a um ou mais dos seguintes objetivos: desenvolvimento de suas cooperativas, eventualmente através da criação de reservas; benefícios aos membros na proporção das suas transações com a cooperativa e apoio a outras atividades aprovadas pelos cooperados.

d) autonomia e independência ${ }^{6}$, segundo o qual as cooperativas são organizações autônomas, de ajuda mútua e controladas pelos seus cooperados. Caso firmem acordo com outras organizações, incluindo instituições públicas, ou recorram ao capital externo, devem fazê-lo em condições que assegurem o controle democrático pelos seus cooperados, mantendo a autonomia das cooperativas.

e) educação, formação e informação, e rege que as cooperativas promovam a educação e a formação dos seus membros e colaboradores, informando o público em geral, sobretudo os jovens e os líderes de opinião, sobre a natureza e as vantagens da cooperação.

f) cooperação entre cooperativas, segundo o qual as cooperativas servem de forma mais eficaz aos seus cooperados e dão mais força ao movimento cooperativo com trabalho em conjunto, através das estruturas locais, regionais, nacionais e internacionais.

g) interesse pela comunidade, e defende que as cooperativas trabalhem para o desenvolvimento sustentado de suas comunidades por meio de políticas aprovadas pelos cooperados. Através do "Dia C"7 as cooperativas de crédito mineiras colocam em prática o interesse pela comunidade.

As cooperativas preocupam-se com a sociedade e o ambiente. Alves (2007, p.249) relata, em seu livro "Economia Solidária, Cooperativismo Popular e Auto-Gestão", que a responsabilidade social está de certa forma, associada aos próprios princípios cooperativistas, já que o sétimo dentre estes é chamado de "interesse pela comunidade". 5 As sociedades cooperativas são classificadas como singulares, ou de 1 grau, as destinadas à prestação direta de serviços aos associados; cooperativas centrais e federações de
cooperativas, ou de 2 grau, aquelas constituídas por cooperativas singulares; confederações de cooperativas, ou de 3 grau, as constituídas por cooperativas centrais e federações
de cooperativas (BRASIL, 1971).
6 Como os associados possuem completa autonomia sobre si mesma e a organização, é também deles a responsabilidade sobre a gestão da cooperativa e, assim, têm o poder sobre
as decisões e o controle da cooperativa, sem que seja necessária a interferência externa para a eficiência e consecução de seu objetivo social, desde que participem efetivamente
do processo decisório (ARAÚJO; SILVA, 2010, p.3,4).
7 Dia de Cooperar é uma iniciativa do Sistema Ocemg/Sescoop-MG que, com o apoio e a participação efetiva das cooperativas de Minas Gerais, tem o objetivo de promover e
estimular a integração das ações voluntárias de todas as cooperativas, cooperados, colaboradores e familiares, em um grande movimento de solidariedade cooperativista (OCEMG, 2011). 
Esses princípios regem o cooperativismo e fundamentam a viabilidade da criação de cooperativas. Para Oliveira (2001, p.319), os sete princípios devem ser incorporados pela gestão, ampliando-os em seus significados originais, para que sejam contempladas as questões de planejamento, organização, direção e avaliação das cooperativas, confirmando a importância destes princípios no fortalecimento do cooperativismo.

\section{GESTÃO DAS COOPERATIVAS}

A gestão pode ser compreendida como uma ciência humana. Sua verdadeira capacidade é testada através de seu exercício diário, que é cheio de criação e entrega de valor com a consequente geração de resultados alinhados com a missão organizacional, transformando complexidade e especialização em desempenho (CHIAVENATO, 2001).

A gestão é idealizada, programada e executada por pessoas. Deste modo, para alcançar seus objetivos, além de contar com suas diversas habilidades pessoais, o gestor tem que contar com a diversidade de valores e habilidades de outras pessoas, nos diversos níveis hierárquicos da organização (MACHADO, 2006, p.60).

Para fazer gestão de cooperativa é necessário ter conhecimento dos limites legais, da diversidade de definições, da evolução histórica e dos princípios cooperativistas. Dentre estes princípios, a gestão democrática pelos membros é diretamente ligada à forma de administrar uma cooperativa. Ou seja, dentro do sistema cooperativista prevalece a autogestão ou gestão participativa (MACHADO, 2006, p.72).

A autogestão ${ }^{8}$ (self-management) das cooperativas do Brasil foi estabelecida com a publicação oficial da Constituição Federal de 1988 - CF/88, o que ocasionou uma nova dinâmica para as mesmas. Exceto as organizações que têm como objeto social o capital, o restante tornou-se livre da ingerência do Estado. Nas cooperativas a gerência é exercida pelos associados - que são os proprietários, ou seja, eles se organizam em um empreendimento coletivo sem um patrão, respeitando o princípio da autogestão. A autogestão é importante para a projeção de um cooperativismo e associativismo com uma nova visão de democracia e de cidadania (ARAÚJO; SILVA, 2010, p.3).

A gestão da sociedade cooperativa é realizada pelos próprios associados, por meio de AssembleiaGeral, que é seu órgão máximo de poder decisório. Na própria Assembleia, os associados elegem os membros da Diretoria ou Conselhos Administrativo e Fiscal e, em alguns casos, outros Conselhos necessários ao seu desenvolvimento nos diversos ramos de atividade (MACHADO, 2006, p.72).

8 Segundo Singer (2003) a autogestão deve ter transparência para que todos tenham acesso às informações e o processo decisório seja eficiente. 
Segundo Valadares (2002a, p.33), a gestão de cooperativa apresenta dois aspectos: “[...] de um lado, o grupo cooperativo (a associação) e, de outro a atividade cooperativa (a empresa), destinada ao serviço das economias individuais associadas."

Cabe aos associados, na condição de proprietários da cooperativa, assumir as decisões coletivas, bem como acompanhar sua execução e seus resultados. Em outras palavras, a participação e o controle democrático da gestão são elementos que constituem o modelo econômico cooperativo, que é embasado no direito de propriedade, mas nem sempre é usufruído, por descaso do próprio associado (VALADARES, 2002a).

Segundo Machado (2006, p. 77), as dificuldades encontradas pelos gestores na administração de uma cooperativa têm, atualmente, gerado questionamentos em alguns pontos da Lei $\mathrm{n}^{\circ} 5.764 / 71$, por guardarem restrições que geram problemas em sua gestão.

Segundo Araújo e Silva (2010, p.4), a governança das cooperativas ${ }^{9}$ é importante porque estas constituem um empreendimento autogestionário de propriedade coletiva, sendo administradas por diretores e levando, às vezes, à necessidade de contratar gestores qualificados e aptos a gerir as cooperativas, já que é comum não havê-los no quadro social. Ainda neste sentido, os autores Cornforth (2004) e Dow (2002) apontam para a necessidade de se trabalhar a governança das cooperativas, dado que esta não é tão bem desenvolvida quanto à governança corporativa (ARAÚJO; SILVA, 2010, p.4).

Segundo Machado (2006, p.43) Os gestores das cooperativas devem se empenhar para promover as condições necessárias para que os princípios do cooperativismo sejam divulgados, respeitados e aplicados.

Os associados, ou cooperados, são a base e a razão de existir de toda cooperativa, já que no sistema de governança corporativa o exercício do poder parte inicialmente destes, nas assembleias. Ou seja, o exercício do comando se dá de baixo para cima (MEINEN; DOMINGUES; DOMINGUES, 2002, p.28).

Ainda neste sentido, Leite e Senra (2005 p.221), afirma que as ações pessoais de cada associado de uma cooperativa de crédito $^{10}$ são as ações da cooperativa, pois estes são, ao mesmo tempo, proprietários e tomadores de serviços prestados. Tal fato possibilita a concessão de empréstimos através da captação de recursos dos próprios associados; enquanto uns contribuem com a aplicação de recursos, outros os tomam, com existência de cooperação entre as partes.

\footnotetext{
9 Sistema que assegura aos sócios - proprietários o governo estratégico da empresa e a efetiva monitoração da diretoria executiva (IBGC, 2012).

10

Nas cooperativas, os indivíduos se associam para utilizar os serviços da sociedade e não para obtenção de um dividendo de capital. Evidentemente, o que ocorre em uma cooperativa é que o cooperado ganha economicamente, mas não se apropria do capital de um terceiro (BIALOSKORSKI NETO, 1997).
} 
Valadares (2003, p.38) afirma que a participação dos associados na tomada de decisão e na administração do negócio é a essência da gestão das cooperativas, reforçando a prática do segundo princípio cooperativo, referente à gestão democrática e livre.

\section{O CASO ESTUDADO}

A pesquisa foi realizada na Cooperativa de Crédito de Livre Admissão da União dos Vales do Piranga e Matipó Ltda, identificada neste artigo pela sigla SICOOB União. Neste capítulo serão descritos os procedimentos metodológicos utilizados na presente investigação. Quanto à abordagem, a pesquisa teve caráter quantitativo. O tipo de pesquisa, quanto aos fins, foi descritivo e quanto aos meios foi um survey. A população total foi de 11789 indivíduos (todos associados). A amostra da presente pesquisa foi definida como não probabilística selecionada por acessibilidade de acordo com Vergara (2005, p.51). O sujeito da pesquisa foi o associado, pois diz respeito à opinião de pessoas que se relacionam com a cooperativa.

O tamanho da amostra pesquisa foi de 373 associados, apresentando nível de significância de 5\% e confiabilidade de $95 \%$ em relação ao universo da pesquisa. O cálculo amostral foi realizado utilizandose a fórmula de dimensionamento conservador para populações de amostra de tamanho finito. Conforme Hair Júnior et al. (2005), este cálculo é realizado quando não se tem uma amostra piloto e deseja-se estimá-la de forma conservadora.

A técnica de coleta utilizada na pesquisa foi o questionário, aplicado no período de 23 a 30 de novembro do ano de 2011. Segundo Malhotra (2006, p.494), o questionário, caracteriza-se como a modalidade de coleta de dados mais adequada para investigações descritivas, como foi o caso da presente investigação.

Para a realização deste estudo foram aplicados, segundo o critério de acessibilidade, 410 questionários aos associados da SICOOB União. Apenas os questionários preenchidos completamente, sem rasuras, foram considerados adequados à utilização para análise, tendo sido eliminados os demais. Sendo assim, foram considerados para análise, 373 questionários.

A escala de avaliação utilizada no questionário foi a de likert ${ }^{11}$ : composta por cinco opções (discordo totalmente, discordo em partes, indiferente, concordo em partes, concordo totalmente), indo de um extremo a outro do conceito, para não confundir os respondentes, com graus de concordância, neutralidade e discordância relativas às assertivas listadas.

Foi realizado um pré-teste, com aplicação do questionário para 10 associados, na sede da SICOOB União, no dia 10 de outubro de 2011. O critério de seleção dos associados foi por acessibilidade. A

11 Escala likertdiz respeito a uma série de afirmações relacionadas ao objeto pesquisado, isto é, representam várias assertivas sobre um assunto Michel (2005, p.23). 
intenção da aplicação deste pré-teste foi eliminar possíveis falhas na aplicação do questionário real, evitando transtornos e permitindo que, ao final da pesquisa, os objetivos propostos neste estudo fossem alcançados. Seus resultados não deverão ser considerados pelo fato de ter-se obtido resposta de apenas dez associados, uma amostra pequena e sem representatividade em relação à população do SICOOB União.

Após a coleta, os dados foram tabulados e analisados. A análise ocorreu através dos softwares estatísticos Minitab 15 e SPSS 16 (Statistical Package for the Social Sciences), além do Microsoft Excel, que auxiliaram na tomada de decisões e conclusões a respeito das hipóteses de estudo para os grupos analisados.

Os métodos estatísticos utilizados na pesquisa consistiram nas análises univariada (análise descritiva das variáveis) e bivariada (análise comparativa entre possíveis associações entre variáveis), conforme desenvolvido por Babbie (1999, p.519).

Durante a análise foram adotadas técnicas estatísticas especificas, de acordo com o tipo de dados obtidos, utilizando-se, na primeira fase, a estatística descritiva, ou seja, ferramentas estatísticas de descrição e apresentação de dados, como tabelas de distribuição de frequência, gráficos expositivos, medidas separatrizes e de tendência central (médias, desvio padrão, mediana e percentil 25 e 75) e coeficiente de correlação.

Para determinar qual recurso seria utilizado no decorrer deste estudo realizou-se um teste de normalidade para os dados, composto pelas seguintes hipóteses: hipótese nula $\left(\mathrm{H}_{0}\right)$ : a variável provém de uma população com distribuição normal (gaussiana) ou hipótese alternativa $\left(\mathrm{H}_{1}\right)$ : a variável não provém de uma população com distribuição normal. (ALMEIDA, 2011).

No caso do teste relativo à variável sexo, em que há apenas dois grupos de estudo a serem comparados (masculino e feminino), foi utilizado o teste não paramétrico de Mann-Whitney (SIEGEL; CASTELLAN, 2006). Para as outras variáveis (com mais de duas categorias) foi utilizado o teste não paramétrico de Kruskal-Wallis (FERREIRA, 2008).

O nível de significância adotado para a decisão e a conclusão sobre os resultados de todos os testes realizados foi de 5\%. Tem-se, portanto, que a confiabilidade conferida às afirmações feitas dentro da análise é de 95\%. Destarte, ao serem montados os testes com as hipóteses nulas e alternativas, optou-se pela rejeição do primeiro caso o p-valor obtido fosse menor ou igual a 0,05; caso contrário a hipótese seria considerada. As hipóteses estarão sempre listadas de acordo com o teste realizado e os p-valores serão exibidos nas tabelas, em conjunto com os demais resultados relevantes. 


\section{ANÁLISES DOS RESULTADOS}

Neste capítulo procede-se à análise dos dados coletados na pesquisa, com base nos objetivos inicialmente propostos, sendo o objetivo geral de avaliar o grau de aderência dos associados de uma cooperativa de crédito de livre admissão de Minas Gerais, no que diz respeito aos princípios cooperativistas, e os três objetivos específicos deste artigo.

\subsection{O PERFIL DO ASSOCIADO}

Primeiramente foram analisados os 8 primeiros gráficos com as distribuições percentuais relativas às variáveis demográficas, para alcançar o primeiro objetivo especifico de identificar o perfil dos associados, com perguntas relacionadas a idade, sexo, tempo de associação, grau de escolaridade, principal atividade econômica, frequência à cooperativa e melhor opção de ser correntista.

Quase metade dos associados abordados encontra-se na faixa etária de 26 a 40 anos, enquanto outros $31 \%$ possuem idade de 41 a 55 anos. Comparando-se as faixas etárias mais extremas, verifica-se que a concentração de pessoas de idade elevada é bastante superior àquela encontrada para as camadas mais jovens (abaixo de 25 anos).

A distribuição percentual relativa ao sexo mostra que a maioria expressiva dos respondentes é formada por homens, dado que a parcela relativa a estes é de 73\%, índice mais do que duas vezes superior ao encontrado para as mulheres $(27 \%)$.

A parcela de respondentes que se associaram ao SICOOB União há menos de 5 anos é de quase $70 \%$, com $48 \%$ situando-se na faixa "1 a 5 anos" e $20 \%$ com um tempo de associação inferior a um ano. Por outro lado, nota-se que uma parcela de $12 \%$ do total de indivíduos pesquisados possui tempo como associados superior a dez anos.

$\mathrm{O}$ perfil dos associados com relação à escolaridade. Observa-se que a maioria expressiva destes (cerca de $73 \%$ ) declara ter concluído apenas o ensino médio ou fundamental, com $40 \%$ das respostas para a última opção. Enquanto isso, a parcela de indivíduos que já possui pós-graduação é de apenas 3\%; outros $24 \%$ possuem ensino superior completo ou ainda não concluído.

Os dados relativos à distribuição percentual acerca do espaço de realização da principal atividade econômica dos associados apontam uma concentração de $60 \%$ destes na área urbana, enquanto a área rural aglomera 39\%. Ressalta-se, ainda, uma pequena parcela de indivíduos que declarou não haver distinção entre as duas áreas para suas atividades econômicas.

Ao serem indagados a respeito da frequência com que vão ao SICOOB União, $36 \%$ dos associados declararam realizar esta atividade diariamente, enquanto $32 \%$ realizam-na uma vez por semana. Verifica-se que a parcela de respondentes que compõem as duas categorias de frequências mais 
espaçadas (mensalmente e quinzenalmente) é de apenas 32\%, bastante inferior às duas primeiras frequências, que concentram $68 \%$ do total.

A opinião dos associados com relação à preferência pelas cooperativas de crédito frente aos bancos. Nota-se que $90 \%$ dos indivíduos pesquisados consideram o SICOOB União a melhor opção para se associar como correntista, enquanto para aqueles que preferem bancos públicos ou privados o percentual é de apenas 10\% (5\% para cada opção).

\subsection{ANÁLISES DO GRAU DE ADERÊNCIA DOS ASSOCIADOS AOS PRINCÍPIOS COOPERATIVISTAS}

Nesta seção foram analisados os 21 gráficos demonstrativos das distribuições percentuais relativas à seção do questionário que avalia o grau de aderência dos associados em relação aos princípios cooperativistas, pretendendo-se alcançar o segundo e o terceiro objetivo específico e o objetivo geral desta dissertação, e responder à questão problema.

A segunda parte do questionário é composta por 21 questões (Q), numerados de Q8 a Q28, sendo:

- Q8: A cooperativa deve impor regras mais severas para a entrada de novos associados, e isso não significa ir contra o princípio da livre adesão.

- Q9: Não é certo que os novos associados tenham direito de usufruir das mesmas coisas que os antigos ajudaram a construir.

- Q10: Quanto mais a cooperativa cresce em número de associados, pior é para mim, pois diminui meu poder de voto.

- Q11: Os votos deveriam ser proporcionais à movimentação do associado na cooperativa.

- $\quad$ Q12 - Não gosto de ir às assembleias, pois elas não decidem nada efetivamente.

- $\quad$ Q13 - Meu voto é muito importante e por isso eu participo ativamente das atividades da cooperativa.

- Q14 - As reservas legais criadas devem servir para gerar benefícios apenas aos associados.

- Q15 - Os associados que não participam e não cumprem o seu papel deveriam sofrer punições, não recebendo as sobras e, em casos extremos, até serem excluídos do quadro social.

- Q16 - A cooperativa deve atender primeiramente aos meus interesses, mesmo que isso lhe traga prejuízos.

- Q17 - As cooperativas são autônomas e independentes, por isto não é importante existir cooperação entre cooperativas. 
- Q18 - O fato das cooperativas não sofrerem influências governamentais as torna mais vulneráveis e pouco competitivas.

- Q19 - As cooperativas não devem ser controladas pelos associados, pois eles não têm conhecimento para realização do controle democrático.

- $\quad$ Q20 - As cooperativas devem atuar na educação de seu associado de forma a desenvolver o cooperativismo e criar pessoas mais solidárias e participativas.

- $\quad$ Q21 - A cooperativa deve se preocupar em prover serviços para os associados e essa história de educação não traz retornos, é só perda de tempo.

- $\quad$ Q22 - Tenho conhecimento do meu saldo em quotas e da distribuição das sobras que a cooperativa realiza anualmente.

- Q23 - A existência de mais de uma cooperativa na cidade enfraquece o cooperativismo.

- Q24 - Investir na comunidade não é uma prioridade da cooperativa. Ela deve atender só as necessidades dos associados.

- $\quad$ Q25 - As cooperativas devem desenvolver projetos em parceria com a comunidade com o intuito de proteger o meio ambiente, incentivar a educação, prevenir doenças, etc.

- $\quad$ Q26 - A cooperativa possui ações para divulgar os princípios cooperativistas.

- $\quad$ Q27 - As ações adotadas pela cooperativa para divulgar o cooperativismo não são eficientes e eficazes. Precisam ser melhoradas urgentemente.

- $\quad$ Q28 - Considero-me um associado aderente aos princípios cooperativistas.

As 21 questões foram separadas em dois grupos, sendo que o primeiro contém 8 questões (Q8, Q13, Q15, Q20, Q22, Q25, Q26, Q28) cuja escala de avaliação crescente é positiva, ou seja, os graus de concordância mais elevados representam uma qualificação positiva relativa aos princípios cooperativistas.

No segundo grupo composto por 13 questões (Q9, Q10, Q11, Q12, Q14, Q16, Q17, Q18, Q19, Q21, Q23, Q24, Q27) a escala é inversa, e valores menores (graus de discordância elevados) são considerados bons indicativos com relação aos princípios cooperativistas.

Através dos itens Q8 a Q25 foi possível alcançar o segundo objetivo especifico que é analisar a compreensão dos associados do SICOOB União quanto às doutrinas cooperativistas, cujas respostas se aproximaram das políticas defendidas pelos princípios cooperativistas, com exceção de apenas duas questões (Q14 e Q15).

O terceiro objetivo especifico de apurar a existência de ações adotadas pela organização com vistas a divulgar os princípios cooperativistas aos associados foi respondido através das questões (Q26 e Q27). 


\subsection{ANÁLISES UNIVARIADAS E BIVARIADAS DOS DADOS DA AMOSTRA}

Ao realizar a análise univariada, foi possível identificar no primeiro grupo, duas variáveis que se destacam pela alta concentração de dados nos graus de concordância mais elevados: Q20 e Q25. Nota-se, para estes dois itens, que as médias são elevadas, os desvios-padrão são razoavelmente baixos e os valores para a mediana e o percentil são também os maiores dentre as oito variáveis listadas.

Contextualizando tais resultados com a descrição contida no questionário, pode-se afirmar que a maioria dos associados apresenta grande concordância com as assertivas de que as cooperativas devem atuar na educação de seus associados, de forma a desenvolver o cooperativismo e criar pessoas mais solidárias e participativas, e de que as cooperativas devem desenvolver projetos em parceria com a comunidade, com o intuito de proteger o meio ambiente, incentivar a educação, prevenir doenças, etc.

No segundo grupo, de modo geral, a avaliação feita pelos respondentes apresenta um perfil positivo, visto que as médias encontram-se, em sua maioria, abaixo do valor 3, e os percentil e medianas também apresentam tendência deslocada para os valores menos elevados.

Para realizar a análise bivariada foram realizados os testes não paramétricos de comparações de médias (Mann-Whitney e Kruskal-Wallis), num total de 147 testes, dos quais 13 apresentaram resultados significativos, indicados por p-valores inferiores ao nível de significância pré-estabelecido, de 5\% apresentados na TAB 1 .

Tabela 1 - Resultados dos testes de comparações de médias para os itens de avaliação da aderência dos associados com os princípios em função das variáveis demográficas

\begin{tabular}{|c|c|c|c|c|c|c|c|}
\hline Item & Idade & Sexo & TACC & Esc & PAE & FIC & MSC \\
\hline Q8 & 0,975 & 0,821 & 0,404 & 0,931 & 0,019 & 0,686 & 0,310 \\
\hline Q9 & 0,248 & 0,192 & 0,148 & 0,419 & 0,827 & 0,431 & 0,424 \\
\hline Q10 & 0,987 & 0,631 & 0,251 & 0,885 & 0,008 & 0,399 & $\mathbf{0 , 0 2 3}$ \\
\hline Q11 & 0,006 & 0,427 & 0,453 & 0,284 & 0,572 & 0,365 & 0,825 \\
\hline Q12 & 0,667 & 0,428 & 0,100 & 0,097 & $\mathbf{0 , 0 1 7}$ & 0,061 & 0,243 \\
\hline Q13 & 0,708 & 0,812 & 0,551 & 0,147 & 0,589 & 0,249 & 0,442 \\
\hline Q14 & 0,731 & 0,704 & 0,512 & 0,330 & 0,578 & 0,054 & 0,171 \\
\hline Q15 & 0,756 & 0,345 & 0,155 & 0,805 & 0,658 & 0,872 & 0,005 \\
\hline Q16 & 0,694 & 0,358 & 0,173 & 0,052 & 0,854 & 0,618 & 0,689 \\
\hline Q17 & 0,855 & 0,095 & 0,872 & 0,629 & 0,909 & 0,887 & 0,346 \\
\hline Q18 & 0,200 & 0,129 & 0,069 & 0,744 & 0,245 & 0,295 & 0,605 \\
\hline Q19 & 0,484 & 0,888 & 0,347 & 0,245 & 0,114 & 0,462 & 0,112 \\
\hline Q20 & 0,992 & 0,310 & 0,005 & 0,103 & 0,308 & 0,161 & 0,731 \\
\hline Q21 & 0,237 & 0,504 & 0,075 & 0,600 & 0,373 & 0,519 & 0,734 \\
\hline Q22 & 0,266 & 0,948 & 0,758 & 0,609 & 0,207 & 0,267 & 0,797 \\
\hline Q23 & 0,544 & 0,849 & 0,615 & 0,193 & 0,211 & 0,258 & 0,367 \\
\hline Q24 & 0,373 & 0,182 & 0,267 & 0,027 & 0,231 & 0,992 & 0,881 \\
\hline Q25 & 0,384 & 0,837 & 0,674 & 0,676 & 0,012 & 0,012 & 0,178 \\
\hline Q26 & 0,221 & 0,337 & 0,715 & 0,649 & 0,014 & 0,073 & 0,014 \\
\hline Q27 & 0,199 & 0,928 & 0,747 & 0,720 & 0,747 & 0,258 & 0,135 \\
\hline Q28 & 0,350 & 0,245 & 0,408 & 0,025 & 0,933 & 0,099 & 0,412 \\
\hline
\end{tabular}

Fonte: Dados da pesquisa 
Os resultados obtidos através das análises bivariadas são as seguintes:

a) Q11: os associados com idade entre 26 e 55 anos acham que os votos deveriam ser proporcionais à movimentação do associado na cooperativa;

b) Q20: os associados que possuem tempo de associação na cooperativa inferior a um ano são os que mais discordam da afirmativa de que as cooperativas devem atuar na educação de seus associados de forma a desenvolver o cooperativismo e criar pessoas mais solidárias e participativas;

c) Q24 e Q28: Os associados com maiores níveis de escolaridade (superior e pósgraduação) têm uma menor aderência aos princípios cooperativistas;

d) Q8, Q10, Q12, Q25, Q26: todos os associados da zona urbana atribuíram valores de concordância significativamente superiores àqueles conferidos pelos respondentes que têm na zona rural sua principal atividade econômica.

e) Q25: os associados que declararam ir à cooperativa mensalmente são os que apresentam maior discordância da afirmativa de que as cooperativas devem desenvolver projetos em parceria com a comunidade com o intuito de proteger o meio ambiente, incentivar a educação, prevenir doenças, etc.;

f) Q10: os associados que consideram o banco privado como a melhor alternativa para ser correntista são aqueles que mais concordam que o aumento no número de associados é prejudicial a eles, pois diminui o poder de cada voto individualmente. Esta afirmativa retrata a realidade dos bancos, mas não das cooperativas, onde o voto é igual para todos.

g) Q15 e Q16: os associados apresentam elevado grau de concordância com as assertivas.

Através deste capítulo de apresentação e análise de resultados, foi possível alcançar o objetivo geral e alcançar os objetivos específicos. No capítulo seguinte serão apresentadas as conclusões da pesquisa, com detalhamento dos objetivos deste artigo e a devida resposta a questão problema.

\section{CONCLUSÕES}

Para a realização deste artigo foi necessária uma revisão bibliográfica sobre o cooperativismo, seus princípios e demais assuntos relacionados ao tema proposto.

Constituiu-se como objetivo geral do trabalho avaliar o grau de aderência dos associados de uma cooperativa de crédito de livre admissão de Minas Gerais, no que diz respeito aos princípios cooperativistas, e como objetivos específicos identificar o perfil dos associados; analisar a compreensão dos associados quanto às doutrinas cooperativistas; apurar a existência de ações adotadas pela 
organização com vistas a divulgar os princípios cooperativistas aos associados. A pergunta que orientou o trabalho foi: qual o grau de aderência dos associados com relação aos princípios cooperativistas?

O primeiro objetivo específico foi alcançado; os resultados obtidos possibilitaram identificar o perfil dos associados, a partir das seguintes categorias: idade, gênero, tempo de associação à cooperativa, grau de escolaridade, principal atividade econômica, frequência à cooperativa e opinião sobre a melhor opção para ser correntista. Conclui-se que o perfil padrão dos associados do SICOOB União são, em sua maioria, do sexo masculino, com idade acima de 26 anos e tempo de associação menor que 5 anos, com ensino fundamental completo, tendo sua principal atividade econômica na área urbana. Sua frequência ao SICOOB União é diária ou semanal, onde considera a cooperativa como a melhor opção para ser correntista.

O segundo objetivo específico foi alcançado; através das questões (Q8 a Q25) foi possível analisar a compreensão dos associados do SICOOB União quanto às doutrinas cooperativistas, com respostas que se aproximaram das políticas defendidas pelos princípios cooperativistas, com exceção da Q14 em que os associados apresentaram uma postura egoísta, não concordando que a cooperativa se beneficie das suas reservas legais e da Q15, onde os associados, em sua maioria não apresentam adesão quanto o seu dever de participar da cooperativa. Conclui-se que para se chegar a respostas positivas apresentando apenas duas exceções é necessário compreender a doutrina cooperativista, que tem, em seus princípios, as linhas orientadoras através das quais as cooperativas levam os seus valores à prática.

O terceiro objetivo específico foi alcançado; com base nos resultados referentes às questões Q26 e Q27 apurou-se que os associados reconhecem a existência de ações, no SICOOB União, orientadas à divulgação dos princípios cooperativistas, apesar de o percentual de associados situados na faixa de neutralidade (“indiferente") na resposta a este item ser considerado significativo.

Conclui-se que, apesar de boa parte dos associados entender que o SICOOB União possui ações para divulgar os princípios cooperativistas, as visões dos respondentes quanto à eficiência e eficácia dessas ações ficam bastante divididas, prevalecendo a opinião negativa, que atenta para a necessidade de melhores práticas neste sentido, objetivando torná-las mais eficientes e eficazes.

O alcance dos objetivos específicos foi favorável ao atendimento do objetivo geral, o qual foi avaliar o grau de aderência dos associados de uma cooperativa de crédito de livre admissão de Minas Gerais, no que diz respeito aos princípios cooperativistas.

Em resposta à questão que norteou este artigo, conclui-se que as distribuições percentuais relativas à seção do questionário que avalia o grau de aderência dos associados no que diz respeito aos princípios cooperativistas, através de 18 questões (Q8 a Q25 e Q28), indicam que 89\% das questões obtiveram respostas positivas, evidenciando elevado grau de aderência dos associados aos princípios cooperativistas e suas práticas, com exceção apenas de duas questões (Q14 e Q15). 
Diante dos resultados apontados e por tratar-se de um estudo quantitativo descritivo, através de survey, pôde-se perceber que o artigo traz como limitação, a impossibilidade do levantamento da totalidade das pesquisas realizadas com relação aos princípios cooperativistas. Neste sentido, sugere-se:

a) avaliar a percepção das pessoas não associadas à cooperativa em relação aos princípios cooperativistas;

b) analisar a percepção dos associados de outros ramos de cooperativas em diferentes estados brasileiros e outros sistemas de cooperativas de crédito;

c) verificar a percepção dos associados sobre a necessidade de reformulação e inclusão de novos princípios, pelo fato de terem sido criados há quase 170 anos: as últimas modificações foram realizadas no XXXI Congresso da ACI, em novembro de 1995, na cidade de Manchester, Inglaterra.

Outra pesquisa também poderia ser realizada, desta vez de forma qualitativa, por meio de entrevista com os diretores, conselheiros e funcionários da cooperativa de crédito, com vistas a ampliar as análises dos resultados desta pesquisa.

\section{REFERÊNCIAS}

ACI. Aliança Cooperativa Internacional. ICA Activities: descreve atividades da ACI. Disponível em: <http://www.ica.coop/activities/un/index.html>. Acesso em: $1^{\circ}$ mai. 2011.

ALMEIDA, Francis Ângelo Marques. Estudo de compreensão sobre os princípios por parte dos associados em uma cooperativa de crédito. Belo Horizonte, 2011, 34p.

ALVES, Francisco de Assis; MILANI, Imaculada Abenante. Sociedades cooperativas: regime jurídico e procedimentos legais para constituição e funcionamento. 2. ed. São Paulo: Juarez de Oliveira, 2003, $37 \mathrm{p}$.

ALVES, Rubem. Filosofia da ciência: introdução ao jogo e suas regras. São Paulo: Loyola, 2007,249p. ARAÚJO, Elisson Alberto Tavares; SILVA, Wendel Alex Castro. Empreendedorismo e Autogestão: Constituição de cooperativas de trabalho http://www.ead.fea.usp.br/semead/12semead/resultado/trabalhosPDF/212.pdf- Inovação, Gestão e Produção. Julho de 2010, vol. 02, n. 15.

ARAÚJO, Elisson Alberto Tavares; SILVA, Wendel Alex Castro. Cooperativas de crédito: a evolução dos principais sistemas brasileiros com um enfoque em indicadores econômico-financeiros. CONTEXTUS. Revista Contemporânea de

Economia e Gestão. v. 09 - Nº 1 - jan/jun 2011. 
BABBIE, Earl. Métodos de Pesquisa Survey. Trad. Guilherme Cezarino. Belo Horizonte: UFMG, 1999, $519 \mathrm{p}$.

BARROS, Lousanne Cavalcanti; SILVA, Silvana Pereira; AMARAL, Hudson; MELO, Alfredo Alves de Oliveira. Análise de Crédito: um estudo empírico em uma Cooperativa de Crédito. ENEGEP 2005 ABEPRO 2156. XXV Encontro Nac. de Eng. de Produção - Porto Alegre, RS, Brasil, 29 out a 01 de Nov. de 2005.

BIALOSKORSKI NETO, Sigismundo. Gestão agroindustrial. GEPAI: Grupo de Estudos e Pesquisas Agroindustriais. São Paulo: Atlas, 1997.

BIALOSKORSKI NETO, Sigismundo. e cooperativas agropecuárias: um ensaio analítico. Viçosa: Universidade Federal de Viçosa, 2002.

BRASIL. Lei n. 5.764 , de 16 de dezembro de 1971. Define a Política Nacional de Cooperativismo, institui o regime jurídico das sociedades cooperativas, e dá outras providências.

Disponível em: < http://www2.camara.gov.br/legin/fed/lei/1970-1979/lei-5764-16-dezembro-1971357788-norma-pl.html>. Acesso em: 3 abril, 2011.

BRASIL. Resolução 3859, de 27 de maio de 2000. Altera e consolida as normas relativas à constituição e ao funcionamento de cooperativas de crédito. Disponível em: <http://www.bcb.gov.br/pre/normativos/res/2010/pdf/res_3859.pdf>. Acesso em: 01 de março. 2012.

BRAGA, C. F. Cooperativismo: noções. 4. ed.S.1.], [s.n.], 2001.

CHIAVEnAtO, Idalberto. Teoria Geral da Administração. 6. ed. rev. atual. 2 v. Rio de Janeiro: Campus, 2001.

CORNFORTH, C. The governance of cooperatives and mutual associations: a paradox perspective. Annals of Public \& Cooperative Economics, v. 75, n. 1, p.11-32, 2004.

CORREIA, Ângela de Castro; MOURA, Kátia Regina Lima. A apreensão da cultura e o não compartilhamento dos valores cooperativistas em uma cooperativa sediada em Natal/RN. Caderno de Pesquisas de Administração, São Paulo, v. 8, n. 04, p. 5. out/dez. 2001.

DOW, G. K. Governing the firm. workers' control in theory and practice. Cambridge (UK). Cambridge: University Press, 2002.

FERREIRA, Armando M. Métodos estatísticos e delineamento experimental: testes não paramétricos. Escola Superior Agrária Castelo Branco. Lisboa, Portugal, 2008.

GAWLAK, A. RATZKE, F. A. Cooperativismo: Filosofia de vida para um mundo melhor. Curitiba: Sesccop/PR-Ocepar, 2001.

HAIR JÚNIOR, Joseph F. et al. Análise Multivariada de Dados. 5. ed. Porto Alegre: Bookmam, 2005, $593 \mathrm{p}$.

HOLZMANN, L. Operários sem patrão: gestão Cooperativa e Dilemas da Democracia. São Carlos: UFSCar, 2001.

\section{INSTITUTO BRASILEIRO DE GOVERNANÇA CORPORATIVA (IBGC). Código das}

Melhores Práticas de Governança Corporativa. Disponível: 〈http:// www.ibgc.org.br>. Acesso em: 20 fev. 2012. 
JANK, M. S.; NASSAR, A. M. Agribusiness e cooperativas no MERCOSUL. São Leopoldo: Perspectiva Econômica, v.30, n.91, p. 13-32, out./dez. 1995.

LEITE, Jacqueline Rosadine de Freitas; SENRA, Ricardo Belízio de Faria. Aspectos Jurídicos das Cooperativas de Crédito. Belo Horizonte: Mandamentos, 2005.

MACHADO, Sandra Mary Cohim Farias. Gestão de Cooperativa: um estudo de caso. Dissertação (Mestrado em Desenvolvimento Humano e Responsabilidade Social) - Faculdade de Ciências Contábeis Fundação Visconde de Cairu., 2006, 167 p.

MALHOTRA, Naresh K. Pesquisa de marketing: uma orientação aplicada. Trad. Laura Bocco. 4. ed. Porto Alegre: Bookman, 2006. 494 p.

MEINEN, Ênio; DOMINGUES, Jefferson Nercolini; DOMINGUES, Jane Aparecida Stefanes. Cooperativas de crédito no Direito brasileiro. Porto Alegre: Sagra Luzzatto, 2002.

MICHEL, Maria Helena. Metodologia e pesquisa científica em ciências sociais: um guia prático para acompanhamento da disciplina e elaboração de trabalhos monográficos. São Paulo: Atlas, 2005, 23p.

NASCIMENTO, Fernando Rios do. Cooperativa como alternativa de mudança: uma abordagem normativa. Rio de Janeiro: Forense, 2000, 209 p.

ORGANIZAÇÃO DAS COOPERATIVAS BRASILEIRAS. O Cooperativismo brasileiro: uma história. Brasília: Versão Br. Comunicação e Marketing, 2009, 150 p.

ORGANIZAÇÃO E SINDICATO DAS COOPERATIVAS DE MINAS GERAIS. Informações econômicas e sociais do cooperativismo mineiro. Belo Horizonte: Gerência Técnica do Sistema Ocemg/Sescoop-MG. 2011.

OLIVEIRA, Djalma de Pinho Rebouças. Manual de gestão das cooperativas: uma abordagem prática. São Paulo: Atlas, 2001, 319 p.

PINHEIRO, Marcos Antonio Henriques. Cooperativas de crédito: história da evolução normativa no Brasil.6. ed. Brasília: Banco Central do Brasil, 2008.

POLONIO, Wilson Alves. Manual das Sociedades Cooperativas. São Paulo: Atlas, 1999.

RECH, Daniel. Cooperativas: uma alternativa de organização popular. Rio de Janeiro: DP\&A, 2000.

RIEVERS, R. Cooperativas de crédito podem facilitar financiamento a microempresas. Disponível em: $\quad<$ http://www.empreendedor.com.br/content/cooperativas-de-cr\%C3\%A9dito-podem-facilitarfinanciamento-microempresas $>$. Acesso em: 11/11/2011.

SANTOS, Boaventura de Sousa (Org.). Produzir para viver: os caminhos da produção não capitalista. Rio de Janeiro: Civilização Brasileira, 2002, p.11.

SCHNEIDER, José Odelso. (Org.). Democracia, participação e autonomia cooperativa.2. ed. São Leopoldo: UNISINOS, 2007.

SIEGEL, S.; CASTELLAN JR., N. J. Estatística Não-Paramétrica para Ciências do Comportamento. Porto Alegre: Artmed, 2006.

SINGER, P. A. Economia Solidária. In: CATTANI, A. D. (Org.). A Outra Economia. Porto Alegre: Veraz, 2003, p. 116-124. 
STEFANO, S.R. ZAMPIER, M. A.; GRZESZCZESZYN, G. Cooperativas: características, gestão e relevância sócio-econômica para o Brasil. In: SEMINÁRIOS EM ADMINISTRAÇÃO - SEMEAD, 9, 2006, São Paulo. Anais... (São Paulo: [s.n.], 2006, 16p.

VALADARES, José Horta. Moderna administração de cooperativas. Belo

Horizonte, maio 2002a. (Apostila FORMACOOP - Mód.II - SESCOOP/BA, realizado em nov. 2004).

VALADARES, José Horta. Estrutura e estratégia institucional: formação de campo organizacional e isomorfismo no cooperativismo de crédito rural de Minas Gerais. 2003, 38 p. Tese (Doutorado em Desenvolvimento, Agricultura e Sociedade) Seropédica: Universidade Federal do Rio de Janeiro. Rio de Janeiro. 2003, 131p.

VERGARA, Sylvia Constant. Projeto e relatórios de pesquisa em administração. São Paulo: Atlas, 2005.

ZYLBERSZTAJN, Decio. Organização de cooperativas: desafios e tendências. Revista de Administração, São Paulo, v.29, n.3, p.23-32, jul./set. 1994. 